\title{
Predatory and suspension feeding of the copepod Acartia tonsa in turbulent environments
}

\author{
Enric Saiz ${ }^{1}$, Thomas Kiørboe ${ }^{2}$ \\ ${ }^{1}$ Institut de Ciències del Mar, CSIC, Passeig de Joan de Borbó $s / n$, E-08039 Barcelona, Spain \\ ${ }^{2}$ Danish Institute for Fisheries and Marine Research, Charlottenlund Castle, DK-2920 Charlottenlund, Denmark
}

\begin{abstract}
The copepod Acartia tonsa exhibits 2 different feeding modes: when feeding on small phytoplankton cells it sets up a feeding current and acts as a suspension feeder; when feeding on motile prey it acts as an ambush feeder. We examined experimentally the effects of small-scale turbulence on feeding rates in these 2 modes. The different feeding behaviours were triggered by offering the copepods diatoms Thalassiosira weissflogii and ciliates Strombidium sulcatum, respectively. Turbulence at 5 different intensities (energy dissipation rate, $\varepsilon$, between $4 \times 10^{-3}$ and $3.7 \times 10^{1} \mathrm{~cm}^{2} \mathrm{~s}^{-3}$ ) was generated by an oscillating grid. In ambush feeding mode, low (realistic) intensities of turbulence $\left(\varepsilon=10^{-3}\right.$ to $10^{-2}$ $\mathrm{cm}^{2} \mathrm{~s}^{-3}$ ) enhanced clearance rates by up to a factor of 4 above those observed in calm water Higher intensities of turbulence $\left(\varepsilon=10^{-1}\right.$ to $\left.10^{1} \mathrm{~cm}^{2} \mathrm{~s}^{-3}\right)$ resulted in a depression of clearance rates, although the rates were still significantly higher than those observed in calm water. The depression of clearance rates at high turbulence intensities was due partly to a decline in capture success, but mainly to a decrease in reactive distance, because turbulence interferes with prey perception by disturbing the hydrodynamical signal generated by motile prey. The negative effects were evident only at turbulence intensities exceeding those normally encountered by $A$. tonsa in its natural habitat. In suspension feeding mode, low intensities of ambient turbulence $\left(\varepsilon=10^{-3}\right.$ to $\left.10^{-2} \mathrm{~cm}^{2} \mathrm{~s}^{-3}\right)$ had negligible effects on clearance rates, while at higher turbulence intensities $\left(\varepsilon=10^{-1}\right.$ to $\left.10^{1} \mathrm{~cm}^{2} \mathrm{~s}^{-3}\right)$ we observed a negative effect (depression of clearance rate). The negative effects become evident when ambient turbulent fluid shear approaches the maximum shear rate of the copepod's feeding current, and we hypothesize that at these intensities the feeding current is eroded. Again the negative effects were observed only at turbulence intensities higher than those typically experienced by $A$. tonsa in the sea. The differential response to turbulence of the 2 feeding behaviours, including the negative effects, were accurately predicted by encounter rate and feeding behaviour models proposed by Kiørboe \& Saiz (1995; Mar Ecol Prog Ser 122:135-145). Because feeding behaviour is specific to the prey (phytoplankton vs motile prey), and because ambush-mode feeding is much more dependent on turbulence than suspensionmode feeding, our findings suggest that prey selection in $A$. tonsa may be partly governed by turbulence in the ocean. This may explain why microzooplankton at times dominates the diet of $A$. tonsa and other copepods, even though it is numerically scarce relative to phytoplankton in the environment.
\end{abstract}

KEY WORDS: Turbulence $\cdot$ Encounter rate $\cdot$ Zooplankton · Predation - Feeding

\section{INTRODUCTION}

Plankton research received a novel impulse with the publication of Rothschild \& Osborn's paper (1988) on the role played by small-scale turbulence for the encounter rates between planktonic predators and their prey. Rothschild \& Osborn (1988) and other theoretical studies (MacKenzie \& Leggett 1991, Yamazaki et al. 1991) have suggested that microscale turbulence may enhance planktonic contact rates and, thus, potentially increase feeding rates in planktonic predators. The amount of actual data available for examining this idea (either lab-or field-generated) is still scarce, but a few studies have confirmed that feeding rates of planktonic predators may in fact be increased in turbulent as compared to calm environments (Alcaraz et al. 1989, Sundby \& Fossum 1990, Saiz \& Alcaraz 1992, Saiz et al. 1992). However, observed enhancements vary considerably, from marginal in suspension-feeding copepods (from 0 to $88 \%$, depending on food concentration, tur- 
bulence intensity and species; Saiz et al. 1992) to substantial in fish larvae (factor of 2 to 4 ; Mackenzie \& Kiørboe in press). A recent modeling study by Kiorboe \& Saiz (1995, this issue) has demonstrated how the swimming and feeding behaviour of both predator and prey, as well as the spatial scales at which the animals operate, lead to very different predictions of the potential effects of microscale turbulence on predator-prey encounter rates.

This study examines experimentally the effect of turbulence on feeding rates in a representative copepod, Acartia tonsa, which is very common in coastal and neritic temperate seas. A. tonsa (as many other copepods) exhibits 2 different feeding modes (Jonsson \& Tiselius 1990). When feeding on phytoplankton, $A$. tonsa generates a feeding current with its feeding appendages and thoracopods, and cells are filtered out of small parcels of water that are squeezed between the second maxillae; the straining mechanism is not completely understood, but it does not seem to be sieving (Price 1988). We term this the suspension feeding mode (Paffenhöfer \& Stearns 1988, Saiz 1994). When foeding on ciliates (and likely other motile prey) $A$ tonsa adopts a different feeding behaviour, which we shall here term the ambush feeding mode (Jonsson \& Tiselius 1990): it does not generate a feeding current but hangs quietly (without moving the feeding appendages) in the water while slowly sinking and scanning the surrounding water for potential prey. The copepod perceives ciliate prey by means of hydromechanical disturbances generated by the swimming ciliate. Once the ciliate is perceived, the copepod reorients itself toward the prey, jumps towards it and attempts to catch it.

Encounter rates depend on velocity differences between predator and prey, and microscale turbulence may increase the velocity difference and, hence, the encounter rate. The model of Kiørboe \& Saiz (1995) predicts that microscale turbulence has a much greater (order of magnitude) effect on encounter rates for predators in the ambush than in the suspension feeding mode. This differential effect is due to the fact that the velocity difference generated by the copepod behaviour (relative to the ambient turbulent fluid velocity) is small for the ambush mode, but comparatively large for the suspension feeding mode.

While turbulence does enhance encounter rates, it also conceivably has some negative effects on feeding rates. Turbulence may interfere with signal transmission and reception as well as capture success in the ambush feeding mode, and it may erode the feeding current in the suspension feeding mode (Saiz et al. 1992, Kiørboe \& Saiz 1995).

The purpose of this study was to examine both the potentially positive and negative effects of microscale turbulence on feeding rates for the 2 feeding modes of Acartia tonsa. We approached this by using 2 different prey: the aloricate ciliate Strombidium sulcatum and the diatom Thalassiosira weissflogii, which trigger, respectively, the ambush and the suspension feeding modes in $A$. tonsa. The implications of oceanic turbulence for foraging and prey selection in $A$. tonsa and other neritic copepods are discussed on the basis of our findings.

\section{MATERIAL AND METHODS}

The research was conducted at the Danish Institute for Fisheries and Marine Research (Charlottenlund). The copepod Acartia tonsa originated from a laboratory culture at the Institute. The culture of the aloricate ciliate Strombidium sulcatum was donated by Dr. Catherine Bernard (Helsingør, Denmark) and originated from a culture kept at the Station Zoologique in Villefranche-sur-Mer (France).

Generation of turbulence in the laboratory and its quantification. Turbulence was generated by means of oscillating stainless steel grids (diameter $13.2 \mathrm{~cm}_{i}$ mesh size $1 \mathrm{~cm}$; open area ca $70 \%$ ). The amplitude of the stroke $(12 \mathrm{~cm})$ covered approximately the entire volume of the experimental containers. A thyristor control allowed us to vary the stroke frequency and consequently the intensity of turbulence. The apparatus was identical to the one described by Kiørboe et al. (1990), except that a different grid was used.

Turbulence (dissipation rates) as a function of grid stroke frequency was estimated by 2 independent methods. First, an ensemble approach was employed following Kiørboe et al. (1990). This approach consisted of quantifying the amount of work exerted by the grid in a stroke and provided an estimate of the rate of energy input into the water volume. The rate of kinetic energy input should equal the rate of turbulent energy dissipation. The second method consisted of determining fluid velocities using small suspended particles (Licopodium pollen; size: $25 \mu \mathrm{m}$ equivalent spherical diameter) as tracers. A black and white $C C D$ video camera hooked up to a VHS videocassette recorder and either mounted on a stereomicroscope or equipped with a $105 \mathrm{~mm}$ macro lens was employed to record the motions. Recording frequency was 50 frames $s^{-1}$ The camera was provided with an adjustable electronic shutter which allowed us to vary the exposure time. The camera was focused in a spot located in the middle of the cylinder and at the midpoint between the wall and the shaft. The grid was run for 15 min at the selected speed before filming Tapes were analyzed on a frame-by-frame basis and the position of the particles on the screen drawn on 
plastic sheets. For the lowest-speed particles, tracking was performed frame by frame and velocities computed at different intervals. For the fastest particles, velocities were determined by measuring the length of the streaks left by the particles and by relating them to the exposure time. The time resolution of the tracks was always at least 2 orders of magnitude higher than the corresponding frequency of grid oscillation. The tracks of the particles were digitized with a tablet hooked up to a computer, and velocity logs for the $x$ and $z$ components were used to estimate turbulent dissipation rates.

Dissipation rates were estimated as the decay of turbulent kinetic energy (TKE) after the grid passed through the view area. Eight (6 at 35 strokes $\mathrm{min}^{-1}$ ) sections of the stroke were chosen for the determination of particle velocities. About 100 particles were tracked in each section.

Turbulent kinetic energy for a given section was computed as:

$$
T K E=\frac{1}{2 n} \sum_{1}^{n}\left[v_{x}^{\prime 2}+v_{y}^{\prime 2}+v_{z}^{\prime 2}\right]
$$

where $v_{x}^{\prime}, v_{y}^{\prime}$ and $v_{z}^{\prime}$ are the fluctuating velocities (that is, after subtracting the mean) for the $x, y$ and $z$ components respectively, and $n$ is the number of particles tracked in that section. The $y$ component of velocity was assumed to equal the one for the $x$ component, thus assuming horizontal isotropy of grid-generated turbulence.

TKE varied with time since the passage of the grid according to the function

$$
T K E=a e^{-b !}
$$

where $t$ is time since the grid passage, and $a$ and $b$ are the function coefficients (see Table 1).

The turbulent dissipation rate $(\varepsilon)$ is given by

$$
\varepsilon=\left|\frac{\partial T K E}{\partial t}\right|=a b \mathrm{e}^{-b t}
$$

and the average turbulent dissipation rates $(\bar{\varepsilon})$ for each stroke frequency were estimated by integrating Eq. (3) through a full stroke and then dividing by the period of the stroke $(T)$ :

$$
\bar{\varepsilon}=\frac{2}{T} \int_{0}^{T / 2} a b \mathrm{e}^{-b t} \mathrm{~d} t=\frac{2}{T}\left(-a \mathrm{e}^{-T b / 2}+a\right)
$$

Five stroke frequencies were examined (Table 1). The values obtained with the ensemble method were somewhat higher than those obtained by particle tracking, but the correspondence between estimates was good (Fig. 1A). The overestimation by the ensemble method can be explained as a result of the fact that it measures the mechanical energy input in the container. Some of this energy input dissipates as turbu-
Table 1. Calibration of the set-up for generating turbulence showing the coefficients for calculating turbulent kinetic energy (TKE, $\mathrm{cm}^{2} \mathrm{~s}^{-2}$ ) as a function of time $(t, \mathrm{~s})$ through a stroke. The estimated values for the exponential fit (Eq. 2) at each stroke frequency (min ${ }^{-1}$ ) and the correlation coefficient (r) are shown

\begin{tabular}{|cccc|}
\hline Stroke frequency & $a$ & $b$ & $r$ \\
\hline 1.3 & 0.107 & 0.404 & 0.918 \\
3 & 0.742 & 0.665 & 0.988 \\
10 & 5.74 & 1.705 & 0.967 \\
20 & 20.5 & 3.336 & 0.934 \\
35 & 29.1 & 3.770 & 0.999 \\
\hline
\end{tabular}
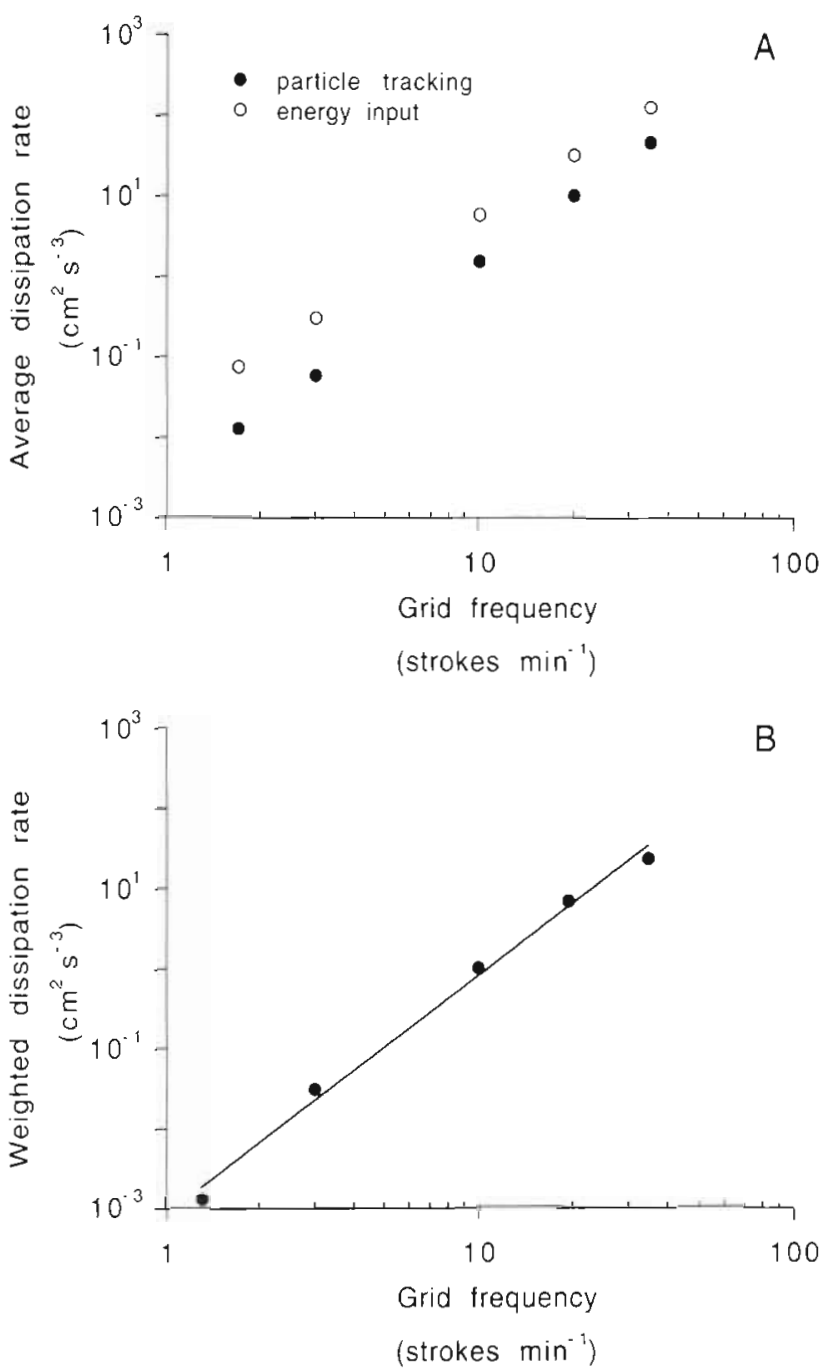

Fig. 1. (A) Plot of the estimated rate of energy input and the estimated average dissipation rate (from particle tracking) at the 5 grid stroke frequencies examined. (B) Weighted dissipation rate as a function of grid stroke frequency (see text for details). Regression line shown. The equation fitted was $\varepsilon=$ $0.00085 \times$ Frequency $^{3.003}, r=0.992$ 
lence, but a fraction would be expected to be 'lost' through the stirring device and walls of the container.

Particle encounter rates due to turbulent fluid motion scale with the dissipation rate raised to the power of 0.33 (Kiørboe \& Saiz 1995). Consequently, we computed a weighted-average dissipation rate $(\hat{\varepsilon})$ from the particle tracking data as follows:

$$
\hat{\varepsilon}=\left[\frac{2}{T} \int_{0}^{T / 2}\left(a b e^{-b t}\right)^{1 / 3} \mathrm{~d} t\right]^{3}=\frac{216 a}{T^{3} b^{2}}\left(1-\mathrm{e}^{-b T / 6}\right)^{3}
$$

Fig. $1 \mathrm{~B}$ shows the relation between the weighted dissipation rates and stroke frequency. Dissipation rates predicted from this relation were used in subsequent calculations.

Experimental design. To examine the effect of turbulence on feeding rates, experiments must be conducted well below saturating food concentrations (see Saiz et al. 1992). While there was enough information in the literature to determine an appropriate range of limiting food concentrations for Acartia tonsa fed Thalassiosira weissflogii (e.g. Paffenhöfer \& Stearns 1988, Saiz et al. 1993), no such information was available for A tonsa feeding on Strombidium sulcatum. Thereforc we first determined the functional response of $A$. tonsa feeding on this ciliate in calm water. These experiments were run at a broad range of food concentrations, ranging from less than 1 cil. $\mathrm{ml}^{-1}$ to ca $130 \mathrm{cil}$. $\mathrm{ml}^{-1}$. Incubations were conducted in $1.20 \mathrm{l}$ screw-cap bottles. The other experimental procedures were the same as those followed for the turbulence experiments (see below).

The experimental design for the turbulence experiments consisted of 1 experimental factor, turbulence intensity, tested at 5 levels and contrasted to a control situation (calm water). The 5 intensities of turbulence selected (see Table 2 for energy dissipation rates estimated for each level) ranged from realistic values for coastal and shelf waters to extremely high values $(\varepsilon$ ca $10^{1} \mathrm{~cm}^{2} \mathrm{~s}^{-3}$ ), probably experienced only occasionally, if ever, in the field (Granata \& Dickey 1991, MacKenzie \& Leggett 1991).

As experimental containers we used Plexiglas cylinders for the stirred condition (i.d. $14 \mathrm{~cm}$; effective vol-

Table 2. Estimated weighted dissipation rates for the different experimental treatments

\begin{tabular}{|cc|}
\hline $\begin{array}{c}\text { Stroke frequency } \\
\left(\mathrm{min}^{-1}\right)\end{array}$ & $\begin{array}{c}\text { Dissipation rate } \\
\left(\mathrm{cm}^{2} \mathrm{~s}^{-3}\right)\end{array}$ \\
\hline 1.7 & $4.0 \times 10^{-3}$ \\
3 & $2.3 \times 10^{-2}$ \\
10 & $8.6 \times 10^{-1}$ \\
20 & $6.9 \times 10^{0}$ \\
35 & $3.7 \times 10^{1}$ \\
\hline
\end{tabular}

ume 2.3 1). As a control (calm condition), parallel screw-cap bottles $(2.3$ l) were incubated on a slowly rotating wheel (end-over-end; $0.2 \mathrm{rpm}$ ). Care was taken to avoid bubbles inside the rotating bottles. A well-sealed constant-speed rotating bottle does not induce internal motion of the water after an initial spin-up period (Jackson 1994). Previous experiments using Thalassiosira weissflogii as prey showed that feeding rates in slowly rotating bottles did not differ from those of animals incubated in still containers (stirred every 5 h to ensure homogeneous suspensions; ANOVA test, $p>0.1$ ).

Three independent experiments were conducted at each turbulence intensity. Each experiment consisted of 4 replicates in turbulence and 4 in still water. Four additional containers without copepods were run at each condition to correct for growth of prey.

Ciliate experiments. Ciliates were grown on bacteria (in wheat-grain medium) in darkness al room temperature. To prepare the experimental suspensions, subsamples of the stock cultures were preserved with Lugol's solution, filtered onto 2 or $5 \mu \mathrm{m}$ membrane filters and counted under a stereomicroscope. The stock culture was then diluted with $0.2 \mu \mathrm{m}$ filtered sea water (with EDTA added to enhance survival; see Jonsson \& Tiselius 1990 ) to the desired concentration. As a general procedure, a small amount of ciliate medium (ca $150 \mathrm{ml}$ ) previously sieved through a $5 \mu \mathrm{m}$ mesh was added to the batch suspension of ciliates to ensure the presence of bacteria in the water during the experiments.

Copepods were sorted the day prior to the experiment and conditioned until the experiment at a saturating concentration of Thalassiosira weissflogil (above $1.5 \mathrm{ppm}$ ) in $1.2 \mathrm{I}$ screw-cap bottles fixed on a turning wheel $(0.2 \mathrm{rpm})$. This procedure ensured some homogeneity in the previous short-term feeding history of the copepods. The acclimated copepods were collected on a submerged sieve and transferred to the experimental containers ( 8 to 23 adult females per container). Two initial 1 l samples were preserved in 1\% Lugol's solution. The experiments were conducted in darkness at $18 \pm 1^{\circ} \mathrm{C}$. At the end of the experiments (ca $24 \mathrm{~h}$ ), $1 \mathrm{l}$ samples were taken from each experimental container and preserved in Lugol's solution. The remaining water was sieved and the number and condition (alive or dead) of the copepods noted. The end-of-experiment Lugol samples were also sieved $(180 \mu \mathrm{m})$ in order to count the copepods in the preserved samples. Mortality of these copepods was estimated from the mortality observed in the unpreserved samples. Ciliate samples were processed and counted as described above. At least ca 300 cells per sample were counted in several transects. If this was not possible or if the cells were not homogeneously distributed on the filter, all cells were counted. 

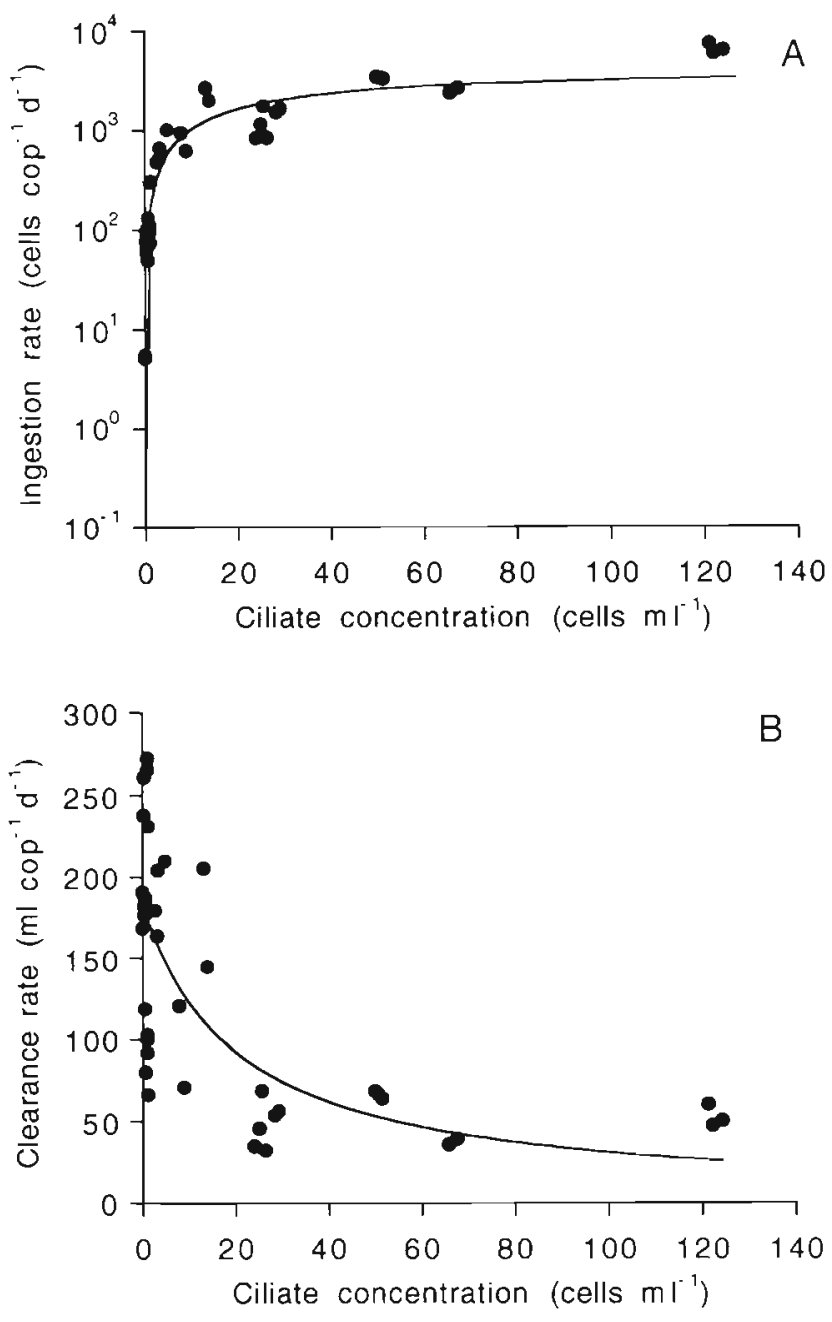

Fig. 2. (A) Ingestion rate of Acartia tonsa fed the aloricate ciliate Strombidium sulcatum in calm water. The line corresponds to Holling type II (Eq. 6) fit to the data $(r=0.892)$. The 3 values at the highest food concentration were not included because they weighted too much in the regression and provided unrealistic parameter values. The fitted parameters were $a=137.5$ and $b=2.45 \times 10^{-4}$ (B) Clearance rate of $A$. tonsa fed Strombidium sulcatum in calm water. The line corresponds to the Holling type II (Eq. 7) fit to the data $(\mathrm{r}=0.724)$.

The fitted parameters were $a=183.2$ and $b=2.69 \times 10^{-4}$

Average food concentrations, clearance and ingestion rates were computed as in Frost (1972).

Although all the experiments regarding turbulence were conducted at the same initial ciliate concentration (4 cells $\mathrm{ml}^{-1}$, below saturation; see 'Results'), there were differences in the actual average food concentrations. This was due to differences in feeding rates between treatments and to differences in the growth rate of ciliates. To solve this problem, the number of copepods in the experimental containers was adjusted to allow similar decreases in the food concentration.
Algal experiments. The general procedures were similar to those mentioned above, except that copepods were starved for ca $20 \mathrm{~h}$ prior to experiments. The number of copepods per container was 27 to 35 . Algal concentrations were estimated as biovolume (ppm or $\mathrm{mm}^{3} \mathrm{l}^{-1}$ ) using an Elzone particle counter fitted with a $120 \mu \mathrm{m}$ orifice tube. Here the total number and survival of copepods were checked at the end of the experiments.

\section{RESULTS}

\section{Functional response of Acartia tonsa feeding on ciliates}

The calm water functional responses of ingestion and clearance rates to the concentration of ciliates are shown in Fig. 2A, B. The ingestion rate increased with ciliate concentration and became saturated at concentrations above $20 \mathrm{cil} . \mathrm{ml}^{-1}$. Accordingly, the clearance rate declines with increasing prey concentration. This response resembles a Holling type II response (Holling 1959) and we thus fitted Holling's disk equation to the data:

$$
I=\frac{a P}{1+a b P}
$$

and

$$
F=\frac{a}{1+a b P}
$$

where $I$ is the ingestion rate (cil. cop. ${ }^{-1} \mathrm{~d}^{-1}$ ), $F$ is the clearance rate $\left(\mathrm{ml} \mathrm{cop} .^{-1} \mathrm{~d}^{-1}\right), P$ is the prey concentration (cil. $\mathrm{ml}^{-1}$ ) $a$ is the 'instantaneous rate of prey discovery' or maximum clearance rate at low food concentration (ml cop. ${ }^{-1} \mathrm{~d}^{-1}$ ), and $b$ is the handling time (d cil. ${ }^{-1}$ ). The fitted parameters (see legend of Fig. 2) suggest a maximum calm-water clearance rate (a) of between 137 (Eq. 6) and 183 (Eq. 7) $\mathrm{ml} \mathrm{d}^{-1}$, and a maximum ingestion rate $\left(b^{-1}\right)$ of between 3723 (Eq. 6) and 4080 (Eq. 7) cil. cop. ${ }^{-1} \mathrm{~d}^{-1}$.

\section{Effect of turbulence on Acartia tonsa clearance rates}

\section{Clearance of ciliates}

We examined the effect of turbulence at ciliate concentrations $<5 \mathrm{ml}^{-1}$, which was well below the calmwater saturating concentration (Fig. 2A). Below this concentration the clearance rate in calm water was independent of food concentration (Fig. $3 \mathrm{~A}, \mathrm{r}^{2}=0.02$, $\mathrm{p}>0.2$ ) and averaged $182 \pm 7.6$ (SE) $\mathrm{ml} \mathrm{d}^{-1}$, close to the estimate of maximum clearance rate from the Holling fit mentioned above. 

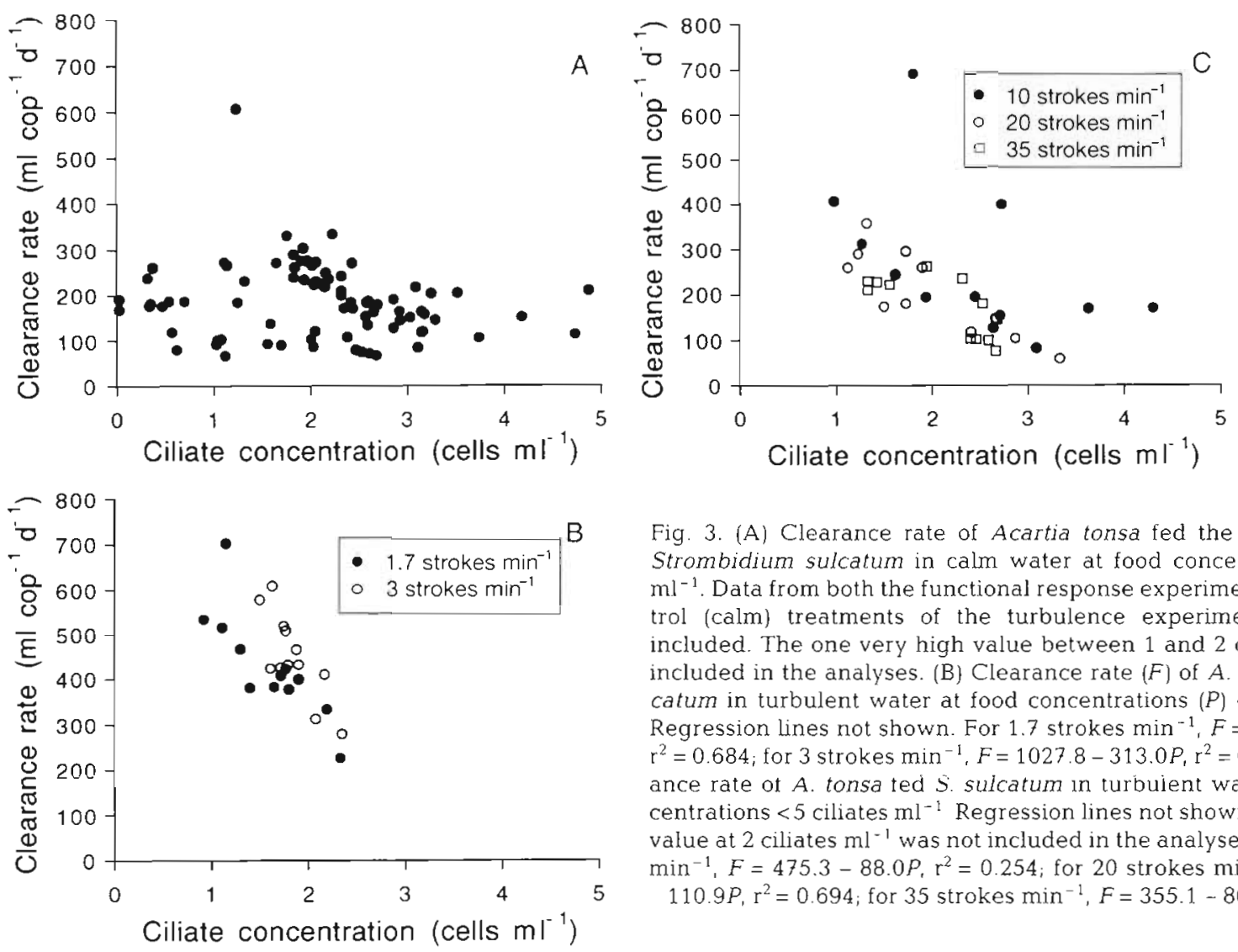

Fig. 3. (A) Clearance rate of Acartia tonsa fed the aloricate ciliate Strombidium sulcatum in calm water at food concentrations $<5$ cil. $\mathrm{ml}^{-1}$. Data from both the functional response experiments and the control (calm) treatments of the turbulence experiments have been included. The one very high value between 1 and $2 \mathrm{cil}^{\mathrm{m} \mathrm{m}^{-1}}$ was not included in the analyses. (B) Clearance rate $(F)$ of $A$. tonsa fed $S$. sulcatum in turbulent water at food concentrations $(P)<5$ ciliates $\mathrm{ml}^{-1}$. Regression lines not shown. For 1.7 strokes $\min ^{-1}, F=787.8-223.3 P$, $r^{2}=0.684$; for 3 strokes min ${ }^{-1}, F=1027.8-313.0 P, r^{2}=0.653$. (C) Clearance rate of $A$. tonsa ted 5 . sulcatum in turbuient water at food concentrations $<5$ ciliates $\mathrm{ml}^{-1}$ Regression lines not shown. The very high value at 2 ciliates $\mathrm{ml}^{-1}$ was not included in the analyses. For 10 strokes $\mathrm{min}^{-1}, F=475.3-88.0 P, \mathrm{r}^{2}=0.254 ;$ for 20 strokes $\mathrm{min}^{-1}, F=428.4-$ $110.9 P, \mathrm{r}^{2}=0.694 ;$ for 35 strokes min ${ }^{-1}, F=355.1-86.1 P, \mathrm{r}^{2}=0.520$

Fig. 3B, C shows the relationship between clearance rate and ciliate concentration at the different turbulence intensities tested. Two effects of turbulence on clearance rate were seen: (1) at all turbulence intensities clearance decreased with increasing food concentration, and (2) at all turbulence intensities maximum clearance rates at low food concentrations were higher than in calm water. Both the slopes and the intercepts of the linear regressions of clearance vs food concentration differed among the 5 treatments (covariance analysis, $\mathrm{p}<0.001$ for both slopes and intercepts).

Table 3. Comparison of maximum observed clearance rates (at 1. cil. $\mathrm{ml}^{-1}$ ) and maximum predicted clearance rates $(\beta$. from the model of Kiørboe \& Saiz 1995) of Acartia tonsa feeding on Strombidium sulcatum at different turbulence intensities. See text for further explanation

\begin{tabular}{|ccc|}
\hline $\begin{array}{c}\text { Dissipation rate } \\
\left(\mathrm{cm}^{2} \mathrm{~s}^{-3}\right)\end{array}$ & $\begin{array}{c}\text { Max. clearance } \\
\pm 95 \% \mathrm{Cl}\left(\mathrm{cm}^{3} \mathrm{~d}^{-1}\right)\end{array}$ & $\begin{array}{c}\beta \\
\left(\mathrm{cm}^{3} \mathrm{~d}^{-1}\right)\end{array}$ \\
\hline 0 & $182 \pm 15.1$ & 193 \\
$4.0 \times 10^{-3}$ & $565 \pm 78.2$ & 477 \\
$2.3 \times 10^{-2}$ & $715 \pm 141.1$ & 701 \\
$8.6 \times 10^{-1}$ & $315 \pm 116.9$ & 1892 \\
$6.9 \times 10^{0}$ & $318 \pm 60.9$ & 3595 \\
$3.7 \times 10^{1}$ & $269 \pm 71.1$ & 6142 \\
\hline
\end{tabular}

The negative relation between Acartia tonsa clearance rates and prey concentration in turbulent water suggests that even at these low prey concentrations ingestion approaches saturation due to higher encounter rates. The copepods appear to 'see' more prey in turbulent water due to enhanced encounter rates.

Maximum clearance rates at each turbulence intensity were estimated as the predicted clearance rate at 1 cil. $\mathrm{ml}^{-1}$ from the linear regressions (Table 3 ). These are conservative estimates of maximum clearances because clearance at concentrations $<1$ cil. $\mathrm{ml}^{-1}$, where we lack observations, might have been higher. At all turbulence intensities maximum clearance rates were higher than that obtained in calm water (Table 3). It is noticeable that there appears to be a dome-shaped relationship between maximum clearance rates and turbulence intensities. Maximum clearance peaked at 3 strokes $\mathrm{min}^{-1}$, reaching values nearly 4 times higher than the observed ones in calm water, and decreased at both higher and lower turbulence intensities.

\section{Clearance of diatoms}

The effect of turbulence on the rate at which Acartia tonsa cleared Thalassiosira weissflogii at food concen- 
Table 4. Comparison of pooled maximum clearance rates of Acartia tonsa feeding on Thalassiosira weissflogii at different turbulence intensities (low: $10^{-3}$ and $10^{-2} \mathrm{~cm}^{2} \mathrm{~s}^{-3}$; high: from $10^{-1}$ to $10^{1} \mathrm{~cm}^{2} \mathrm{~s}^{-3}$ ). Maximum clearance rates are estimated from the regressions between clearance rate and food concentration (data shown in Fig. 6) at a food concentration of 0.2 ppm.

\begin{tabular}{|cc|}
\hline Turbulence intensity & $\begin{array}{c}\text { Max. clearance rates } \pm 95 \% \mathrm{CI} \\
\text { (ml cop }^{-1} \mathrm{~d}^{-1} \text { ) }\end{array}$ \\
\hline Calm & $76 \pm 5.4$ \\
Low & $68 \pm 9.3$ \\
High & $43 \pm 8.9$ \\
\hline
\end{tabular}

trations below 0.6 ppm was examined; this is below the calm-water saturating concentration (Paffenhöfer \& Stearns 1988, Saiz et al. 1993). Unlike the clearance rates on ciliates, no positive effects of turbulence were found for diatoms (Figs. 4A to C). For statistical purposes we pooled the experiments together into 3 groups: zero (calm water), low (experiments run at 1.7 and 3.0 strokes $\mathrm{min}^{-1}$ ) and high (experiments performed at 10,20 and 35 strokes $\mathrm{min}^{-1}$ ) turbulence. Covariance analysis performed on log-transformed data (to correct for heteroscedasticity in variance) showed that although there were no differences in the slopes, the intensity of turbulence had a significant negative effect on the intercepts of the regressions between clearance rate and food concentration ( $\mathrm{p}<$ $0.0001)$.

Maximum clearance rates were estimated at a food concentration of $0.2 \mathrm{ppm}$ (Table 4). At low turbulence maximum clearance rates were similar to those measured in calm water, while at higher turbulence intensities clearance rates were significantly lower than those measured in calm and low turbulence water.

\section{DISCUSSION}

We found very different responses of Acartia tonsa to turbulent fluid motion depending on the feeding mode exhibited. Feeding rates were substantially increased for ambush-feeding $A$. tonsa at moderate intensities of turbulence $\left(\varepsilon=10^{-3}\right.$ to $10^{-2} \mathrm{~cm}^{2} \mathrm{~s}^{-3}$; up to $293 \%$ enhancement), while at these same intensities clearance rates for suspension-feeding copepods were unaffected. At the highest intensities of turbulence $(\varepsilon=$ $10^{-1}$ to $10^{1} \mathrm{~cm}^{2} \mathrm{~s}^{-3}$ ) $A$. tonsa experienced declining clearance rates in both feeding modes. At moderate intensities of turbulence these observations agree with the predictions of the encounter rate model of Kiørboe \& Saiz (1995), while the response at higher intensities can be explained by taking into account potential changes in capture success and reaction distance of the copepod. Below we first discuss the effects on both
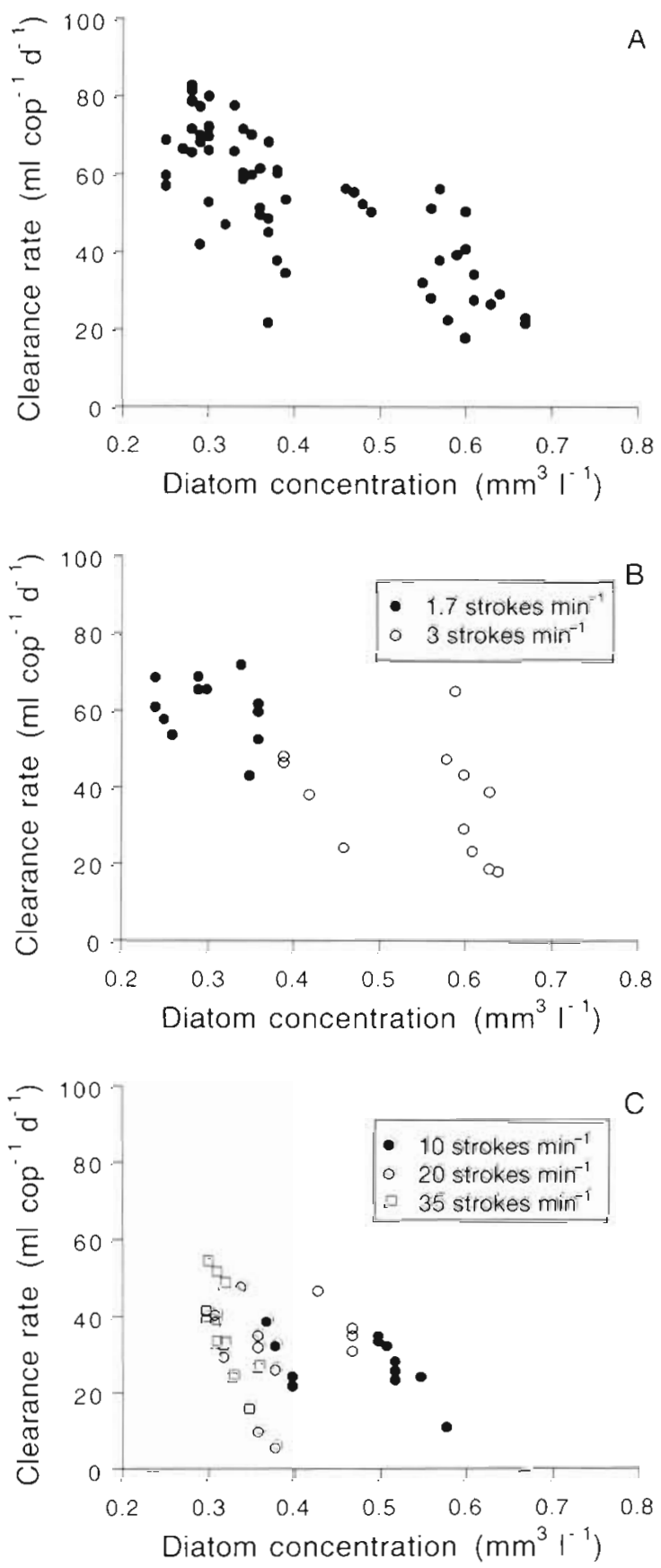

Fig. 4. (A) Clearance rate of Acartia tonsa feeding on the diatom Thalassiosira weissflogii in calm water. (B \& C) The same as (A), but in turbulent water

feeding modes in further detail, and subsequently consider some of their possible ecological implications.

\section{Ambush feeding mode}

The encounter rate model of Kiorboe \& Saiz (1995) predicts that the (maximum) clearance rate $(\beta)$ of a 
passively sinking ambush feeding Acartia tonsa with a $100 \%$ capture efficiency (i.e. all encountered prey items are captured) in calm water is:

$$
\beta=\pi\left(r_{1}+r_{2}\right) v_{1}
$$

where $r_{1}$ is the reactive distance (up to $0.1 \mathrm{~cm}$ for ciliates; Jonsson \& Tiselius 1990), $r_{2}$ is the radius of the prey (Strombidium sulcatum, $15 \times 10^{-4} \mathrm{~cm}$ ), and $v_{1}$ is the sinking velocity of the predator $\left(0.069 \mathrm{~cm} \mathrm{~s}^{-2}\right.$; Jonsson \& Tiselius 1990). This calculation ignores encounters due to sinking and motility of the ciliates. The sinking velocity of $S$. sulcatum is ca $0.002 \mathrm{~cm} \mathrm{~s}^{-1}$ and at bacterial concentrations exceeding $10^{6} \mathrm{ml}^{-1}$ the ciliate exhibits a positive population growth and has negligible motility (Fenchel \& Jonsson 1988). Since we added bacteria to our experimental containers, and because the ciliates were growing during incubations in terms of both numbers and of biomass, this is a reasonable assumption.

For turbulent water the predicted clearance rate is:

$$
\beta_{\varepsilon}=\pi\left(r_{1}+r_{2}\right)^{2} v_{1}+1.37 \pi \varepsilon^{\frac{1}{3}}\left(r_{1}+r_{2}\right)^{\frac{7}{3}}
$$

where $\varepsilon$ is the dissipation rate.

Table 3 compares clearance rates calculated from Eqs. (8) \& (9) with the clearance rates observed at low prey concentration $\left(1\right.$ cil. $\left.\mathrm{ml}^{-1}\right)$. In calm water and at 1.7 and 3.0 strokes min ${ }^{1}$ there is a very good correspondence between observed and predicted values. This correspondence suggests that the capture efficiency is actually close to $100 \%$, as was also found for Acartia tonsa feeding on a related ciliate species (Strombidium reticulatum) by Jonsson \& Tiselius (1990). It is also consistent with the observation that $S$. sulcatum seems to have a weak escape response to predators (see below). However, at higher turbulence intensities, predicted values considerably exceed observed values. The same pattern is evident if we replot the functional response, but replace the prey density $(P)$ with apparent prey concentration $P\left(\beta_{\varepsilon} / \beta_{0}\right)$ (Fig. 5). $\beta_{\varepsilon} / \beta_{0}$ is the ratio by which prey encounter rate in turbulent water is increased over that in calm water according to the model, and $P\left(\beta_{\varepsilon} / \beta_{0}\right)$ is thus the prey density that the copepod actually perceives. The functional responses of ingestion rate to apparent prey concentration at both 1.7 and 3.0 strokes $\mathrm{min}^{-1}$ are now well explained by the calm-water functional response curve (Fig. 5). Thus, the encounter rate model accurately predicts feeding rates of $A$. tonsa at moderate intensities of turbulence. At higher turbulence intensities, however, observed ingestion rates tend to be well below the functional response values in calm water.

The explanation for this discrepancy between the model predictions and the observed clearance rates at high turbulence levels might be a change in capture

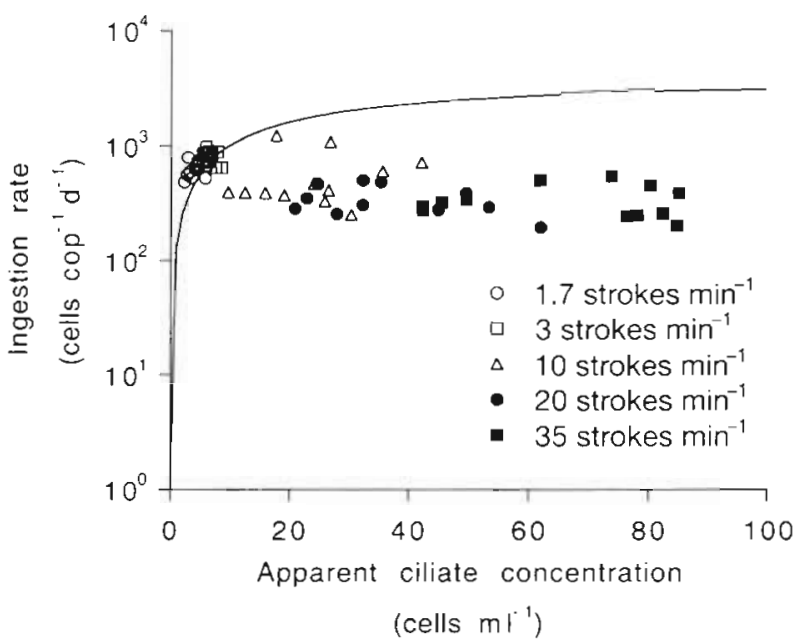

Fig. 5. Ingestion rate of Acartia tonsa fed the aloricate ciliate Strombidium sulcatum as a function of the apparent food concentration (taking into account the increased encounter rate in turbulent water). The line is the Holling type II fit in calm water shown in Fig. 2A

efficiency and/or reaction distance in the presence of turbulence, 2 variables assumed to be constant in the model presented by Kiørboe \& Saiz (1995). Both of these may, however, be negatively influenced by turbulence (Saiz et al. 1992). In the following we examine the dependency of capture success and reaction distance on turbulence.

Due to turbulence, encountered prey may be advected out of the copepod's reaction sphere faster than the copepod can react (Granata \& Dickey 1991, MacKenzie et al. 1994). Kiørboe \& Saiz (1995) provided an expression (modified from MacKenzie et al. 1994) for the likelihood that encountered prey are advected away prior to capture. This likelihood is a function of the turbulent velocity, of the predator's reaction distance and of its reaction time.

By assuming a reaction time of Acartia tonsa to ciliates of $0.1 \mathrm{~s}$ (Jonsson \& Tiselius 1990) and a reaction distance of $0.1 \mathrm{~cm}$ we calculated the capture success $(\delta)$ and corresponding clearance rates $(\delta \beta)$ as a function of turbulence intensity using the model of Kiørboe \& Saiz (1995) (Table 5). Only at very high intensities of turbulence is the capture success significantly affected. The estimated decline in capture success with increasing turbulence is insufficient to account for the observed variation in clearance rate. The analysis demonstrates, however, that at typical intensities of turbulence in the ocean $\left(\varepsilon<10^{-1} \mathrm{~cm}^{2} \mathrm{~s}^{-3}\right)$ capture success is not depressed much due to prey being advected out of the reaction sphere of the copepod $(\delta>96 \%)$.

We next examine the potential effect of turbulence on reaction distance. Acartia tonsa is believed to per- 
ceive the hydromechanical signal generated by a swimming prey by means of mechanoreceptors on the first antennae (Jonsson \& Tiselius 1990). Turbulence may interfere with this hydromechanical signal, thereby reducing the effective reaction distance. Kiørboe \& Saiz (1995) modeled the relationship between reaction distance $(r)$ and energy dissipation rate $(\varepsilon)$ and found

$$
r=\left(\frac{1}{r_{0}{ }^{2}}+\frac{b \varepsilon K_{\mathrm{c}}}{S}\right)^{-0.5}
$$

where $r_{0}$ is the calm-water reaction distance, $S$ is the signal strength, $K_{\mathrm{c}}$ is the critical signal-to-noise ratio, and $b$ is a proportionality constant.

Empirical estimates of reaction distances were obtained by equating the observed clearance with $\beta$ and solving for reaction distance $\left(r_{1}\right)$ in Eq. (9). The resulting estimates of reaction distance as a function of $\varepsilon$ have been plotted in Fig. 6 , which also shows the fit of Eq. (10) to the data. Because the observed relationship has the form predicted by Eq. (10), this suggests that a large fraction of the unexplained variation in clearance rate with turbulence intensity can in fact be accounted for by changes in the reaction distance.

One aspect that we have not considered in the discussion above is the behaviour of the prey. If turbulence negatively affected the ability of the prey to escape, the clearance rates would be higher. This does not seem to be the case in our experiments because Strombidium sulcatum has a weak escape response (no jumping ability; Jonsson \& Tiselius 1990, Bernard pers. comm.). Also, the good agreement between the model predictions and the experimental data at low turbulence suggests a high capture success and consequently a low escaping ability.

Table 5. Acartia tonsa fed the ciliate Strombidium sulcatum. Maximum observed clearance rates (at $1 \mathrm{cil}^{\mathrm{ml}} \mathrm{ml}^{-1}$ ), capture success $(\delta)$ and corrected maximum predicted clearance rate $(\delta \beta) . \delta$ is calculated by assuming a constant reaction distance of $0.1 \mathrm{~cm}$ and a reaction time of $0.1 \mathrm{~s}$, and employing the model of MacKenzie et al. (1994) as modified by Kiørboe \& Saiz (1995). The corrected clearance rate is the product of capture success $(\delta)$ and the maximum clearance rate $(\beta)$ predicted from the model of Kiørboe \& Saiz (1995)

\begin{tabular}{|cccc|}
\hline $\begin{array}{c}\text { Dissipation rate } \\
\left(\mathrm{cm}^{2} \mathrm{~s}^{-3}\right)\end{array}$ & $\begin{array}{c}\text { Obs. clearance } \\
\pm 95 \% \mathrm{CI}\left(\mathrm{cm}^{3} \mathrm{~d}^{-1}\right)\end{array}$ & $\delta$ & $\begin{array}{c}\delta \beta \\
\left(\mathrm{cm}^{3} \mathrm{~d}^{-1}\right)\end{array}$ \\
\hline 0 & $182 \pm 7.6$ & 1.0 & 193 \\
$4.0 \times 10^{-3}$ & $565 \pm 35.1$ & 0.98 & 467 \\
$2.3 \times 10^{-2}$ & $715 \pm 63.3$ & 0.96 & 673 \\
$8.6 \times 10^{-1}$ & $315 \pm 51.7$ & 0.86 & 1627 \\
$6.9 \times 10^{0}$ & $318 \pm 27.3$ & 0.68 & 2445 \\
$3.7 \times 10^{1}$ & $269 \pm 31.9$ & 0.33 & 2027 \\
\hline
\end{tabular}

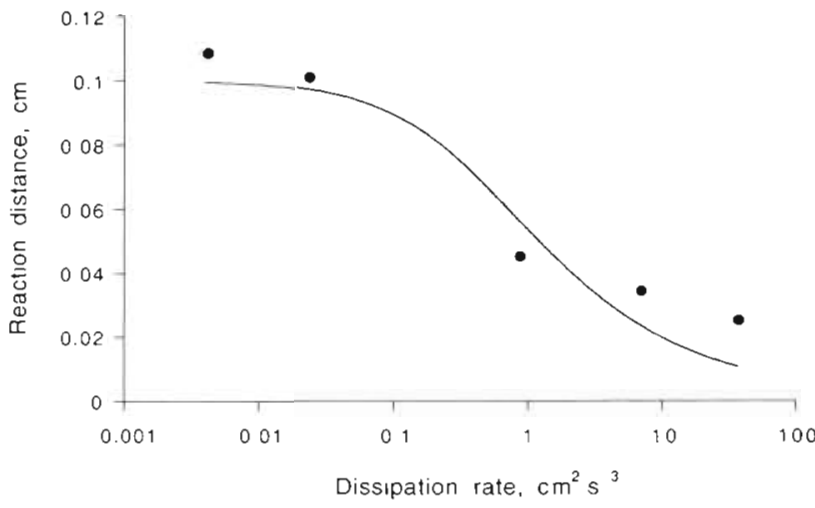

Fig. 6. Estimated change in reaction distance of Acartia tonsa to the ciliate Strombidium sulcatum as a function of turbulence dissipation rate assuming constant capture efficiency. The line is the least-squares fit of Eq. (10) to the data. See text for further explanation

\section{Suspension-feeding mode}

The clearance rate of a suspension-feeding copepod in calm and turbulent water can also be predicted by Eqs. (8) \& (9), but the parameters $r_{1}$ and $v$ must be interpeted somewhat differently (Kiørboe \& Saiz 1995). When a suspension-feeding copepod creates a feeding current, a large volume of water is scanned by its feeding appendages (Strickler 1985). However, only a fraction of the water in the feeding current passes through the volume (the capture volume) that can be reached by the food-collecting feeding appendages (in Acartia tonsa the second maxillae; Paffenhöfer \& Stearns 1988). Many suspension-feeding copepods are able to detect phytoplankton cells at a distance as they are approaching in the accelerating feeding current (i.e. before making physical contact). On perceiving the cells the copepods reroute them into the water that passes through the capture volume, thus increasing the effective volume of water scanned. Only particles passing through this volume can be captured. Within this volume parcels of water are squeezed between the feeding appendages, and the particles are thereby strained (Strickler 1985).

Acartia tonsa appears to lack the ability to reroute cells (Paffenhofer \& Stearns 1988). Furthermore, it is not known whether $A$. tonsa is able to select those parcels of water within the capture volume that contain particles, or whether the straining motions of the maxillipeds are simple, automatic and with no behavioural response. In the latter case turbulence will not increase the particle capture rate and, hence, clearance and ingestion rates of the copepods. If, however, particles within the capture volume can be sensed individually (as in other copepods), the functional reaction distance $\left(r_{1}\right)$ is given by the length of the 2 nd max- 
illae, and the relevant current velocity is that at distance $r_{1}$ from the copepod (Kiørboe \& Saiz 1995). The 2nd maxilla of $A$. tonsa measures about $0.02 \mathrm{~cm}$, and the feeding current velocity at this distance from the copepod is ca $0.8 \mathrm{~cm} \mathrm{~s}^{-1}$ (Jonsson \& Tiselius 1990). The diameter of the diatom Thalassiosira weissflogii is about $12 \times 10^{-4} \mathrm{~cm}$. Inserting these values in Eq. (8) yields a calm-water clearance rate of $92 \mathrm{ml} \mathrm{d}^{-1}$. The observed calm-water clearance rates of 60 to $80 \mathrm{ml} \mathrm{d}^{-1}$ at low food concentrations are close to this value. The predicted effect of turbulence in this scenario is small; inserting the same values in Eq. (9) yields 99 and $104 \mathrm{ml} \mathrm{d}^{-1}$ at 1.7 and 3.0 strokes $\min ^{-1}\left(\varepsilon=4 \times 10^{-3}\right.$ and $2.3 \times 10^{-2} \mathrm{~cm}^{2} \mathrm{~s}^{-3}$ ), corresponding to 7 and $13 \%$ increases in clearance rates, respectively. Given the variability in our measurements, we would not have been able to detect such small enhancements. In similar experiments with $A$. tonsa, Saiz et al. (1992) found a statistically significant increase of ca $26 \%$ in clearance rates at dissipation rates $>10^{-1} \mathrm{~cm}^{2} \mathrm{~s}^{-3}$ (Alcaraz pers. comm.); this is also consistent with the model prediction of $21 \%$ at such a high dissipation rate. Thus, both model predictions and observations suggest that the effect of turbulence on clearance and ingestion rates in the suspension feeding mode is small at intensities typical of the habitats occupied by $A$. tonsa, and about an order of magnitude less than the effect on these rates in the ambush feeding mode.

At higher intensities of turbulence our observations show a negative influence on clearance rates (Table 4), while Eq. (9) predicts increases of 45,89 and $156 \%$ respectively at 10,20 and 35 strokes $\mathrm{min}^{-1}$. We suggest that this negative influence is due to ambient fluid motion interfering with or destroying the feeding current. The maximum current shear generated by suspension-feeding Acartia tonsa is about $10 \mathrm{~s}^{-1}$ (Jonsson \& Tiselius 1990; see also Kiørboe \& Saiz 1995). The negative effects of turbulence in our experiments became evident at 10 strokes min $^{-1}$ (Fig. 4). The fluid shear generated at this turbulence intensity can be calculated from the energy dissipation rate as $(\varepsilon / v)^{0.5}$, where $v$ is the kinematic viscosity (ca $10^{-2} \mathrm{~cm}^{2} \mathrm{~s}^{-1}$ ). Thus, at 10 strokes min $^{-1}$ the ambient fluid shear is $9 \mathrm{~s}^{-1}$. This suggests that when the ambient fluid shear approaches the shear generated by the copepod's feeding current, the latter is being disturbed or eroded. Note, however, that such high dissipation rates rarely, if ever, occur in the habitats occupied by $A$. tonsa.

\section{Implications for copepod feeding rates and prey selection}

In coastal areas, where Acartia tonsa occurs, typical intensities of turbulence are on the order of $10^{-3}$ to $10^{-2}$ $\mathrm{cm}^{2} \mathrm{~s}^{-3}$ (Granata \& Dickey 1991). At about this level of turbulence we found the highest turbulence-enhanced feeding rates for $A$. tonsa in the ambush feeding mode. Thus, ambush-feeding $A$. tonsa appear to be well adapted to the ambient levels of turbulent fluid motion experienced in their habitat.

The observed substantial enhancement of feeding rate (a factor of ca 4) has obvious implications for the performance of Acartia tonsa in the sea. Previously reported copepod clearance and ingestion rates on ciliates (see review by Stoecker \& Capuzzo 1990) are likely to have severely underestimated performance in the field because they were estimated in calm water conditions. The grazing impact of copepods on ciliate (microplankton) communities in the field probably will have to be reconsidered in the light of the significant enhancement of predation rates by copepods found in our study at common turbulence intensities. For the suspension feeding mode, however, realistic levels of ambient turbulent fluid motion have relatively little effect on feeding rates, and deleterious effects only occur at turbulence intensities exceeding typical field intensities.

The differential effect of small-scale turbulence on suspension and predatory feeding has implications for optimal foraging and prey selection in Acartia tonsa and other copepods that can switch between ambush and suspension feeding modes (e.g. several species of Acartia and Centropages; Tiselius \& Jonsson 1990). The dietary composition of planktonic copepods is currently under debate, and the classical view that copepods feed predominantly on diatoms has recently been challenged (e.g. Gifford 1993, Kleppel 1993). Gut content analyses have shown that animal prey frequently dominates the diet of planktonic copepods, in particular when the concentration of diatoms is relatively low and the abundance of ciliates and other microzooplankton is relatively high (reviewed in Kiørboe \& Nielsen 1994). Diatoms and other non-motile phytoplankton prey can only be captured in the suspension feeding mode, since they cannot be perceived by mechanoreceptors and because chemical perception requires a feeding current (Strickler 1985). Conversely, capture of ciliates - and likely other microzooplankton prey - is probably very inefficient in the suspension feeding mode, because the prey may be able to sense and escape the feeding current. We suggest, therefore, that microzooplankton prey are only efficiently captured in the ambush feeding mode. Thus, a switch in feeding mode implies a shift in prey selection. Depending on the relative concentrations of diatoms and ciliates in the environment, $A$. tonsa should 'choose' the feeding mode that results in the highest carbon gain or ingestion rate. In Fig. $7 \mathrm{~A}$ we compare the functional responses in ingestion rate to the concentration of Strombidium sulcatum and Thalassiosira weissflogii respectively (the 
latter adapted from Saiz et al. 1993) in calm and turbulent water $\left(\varepsilon=10^{-2} \mathrm{~cm}^{2} \mathrm{~s}^{-3}\right)$. Fig. $7 \mathrm{~B}$ is based on the functional responses in Fig. $7 \mathrm{~A}$ and shows the concentrations of ciliates and diatoms at which the respective ingestion rates are equal. Above the line, the ingestion rate on ciliates exceeds that on diatoms, and optimal foraging theory predicts a switch to ambush feeding and a diet consisting of ciliates. At concentrations of ciliates and diatoms that fall below the line we would conversely predict suspension feeding and a diet composed of diatoms. The effect of turbulence is to shift the borderline to the right, i.e. to increase the range of relative concentrations where we predict ambush feeding and ciliate diets. Thus, we predict that the effect of turbulence is to change prey selection. The exact position of the lines of course depends on the exact shape of the functional responses, which may differ between prey items, but the effect of this difference would be marginal in this double logarithmic representation.

As an illustrative example we also plotted (Fig. 7B) observed concentrations of ciliates vs concentrations of diatoms as recorded during a study covering a complete seasonal cycle at a shallow $(30 \mathrm{~m})$ coastal site in the Kattegat $\left(56^{\circ} 15^{\prime} \mathrm{N}, 12^{\circ} 00^{\prime} \mathrm{E}\right)$ (Kiørboe \& Nielsen 1994). Assuming calm-water functional responses, one would predict that Acartia tonsa would suspensionfeed on almost all observation days, and have a diet composed mainly of diatoms (and other phytoplankton). However, assuming a turbulence intensity of $10^{-2} \mathrm{~cm}^{2} \mathrm{~s}^{-3}$ the prediction changes: during most of the year, when diatom concentrations are relatively low, $A$. tonsa is expected to feed mainly on ciliates; only during periods of high diatom abundance (the spring bloom) are the copepods expected to switch to a diatom diet. From independent evidence (functional relationships between egg production rates and ambient concentrations of ciliates and large phytoplankton) Kiørboe \& Nielsen (1994) argued that the latter was in fact the case. Thus, the effect of turbulence may explain the inferred seasonal variation in diet composition. For the same study site, Nielsen \& Kiørboe (1994) found that the populations of ciliates were always growing at maximum rates and, thus, were never food limited. They also showed that the co-occurring copepod populations had sufficiently high clearance rates to potentially control the populations of ciliates throughout the year. The latter point is reinforced by the higher clearance rates in turbulent water observed in the present study. In spite of this, Nielsen \& Kiørboe (1994) observed that ciliate abundance largely followed the seasonal variation in concentration of phytoplankton. Fig. 7B suggests that during periods of high diatom concentrations, the copepods switch to a diatom diet, thus allowing the ciliate populations to escape predator control and to increase in abundance.
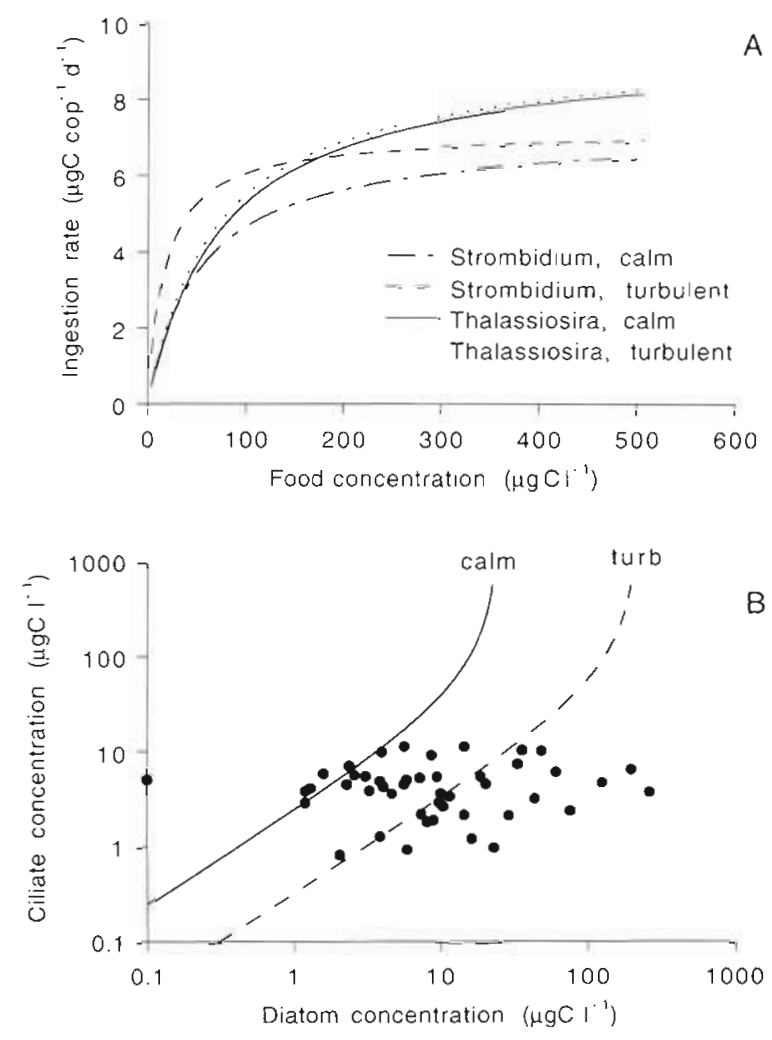

Fig. 7. (A) Ingestion rate of Acartia tonsa fed either diatoms Thalassiosira weissflogij or ciliates Strombidium sulcatum in calm and turbulent $\left(\varepsilon=10^{-2} \mathrm{~cm}^{2} \mathrm{~s}^{-3}\right)$ water The ciliate calmwater curve is the Holling fit from Fig. $2 \mathrm{~A}$. The diatom calmwater curve is a Holling fit to data in Saiz et al. (1993). The curves for the turbulent condition were generated by increasing the 'instantaneous rate of prey discovery' (a in Eq. 6) as predicted by the model of Kiørboe \& Saiz (1995). For S. sulcatum an average cell volume of $14663 \mu^{3}$ was employed. A

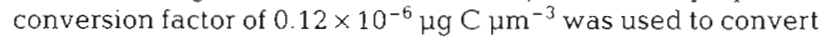
cell volume to carbon for both $T$. weissflogii and S. sulcatum. See further details in the text. (B) The lines indicate the concentrations of diatoms $T$. weissflogii and ciliates S. sulcatum at which the ingestion rates of $A$. tonsa are the same on both diets. The continuous line corresponds to calm water conditions, while the dashed line corresponds to a turbulence intensity of $\varepsilon=10^{-2} \mathrm{~cm}^{2} \mathrm{~s}^{-3}$. The data points correspond to observed concentrations of diatoms and ciliates in the Kattegat (Kiørboe \& Nielsen 1994). See text for further details

\section{CONCLUSIONS}

This study has shown that ambush-feeding copepods substantially enhance their feeding rates in turbulent environments, while suspension-feeding copepods are only marginally affected at realistic intensities of turbulence. These results are in full agreement with the predictions of the model study of Kiorboe \& Saiz (1995). This differential response to turbulence by copepods exhibiting either predatory or suspension feeding behaviours has major implications for the extrapolation 
of laboratory-measured feeding rates to the sea, for the performance and distribution of copepods in the sea, and for prey selection. The latter aspects need further verification, but testable hypotheses immediately emerge from the predictions made by Fig. 7B: the prey selection of Acartia tonsa offered a mixture of diatoms and ciliates should be directly dependent on the intensity of ambient turbulent fluid motion. We plan to examine this prediction in our future work.

Acknowledgements. The authors are indebted to Sebastian Beck, Malene Carlsen, Ken Cornelisse, Susanne Klem, Camilla Mikkelsen and Jack Melbye for technical support. Drs S. Jonasdottir and M. Sabatini provided moral support to E.S. during the dark Scandinavian winter. Conversations held with Dr B. MacKenzie and comments to the manuscript by Drs C. Bernard, G. Jackson, P. R. Jonsson, T R. Osborn and P. Tiselius are acknowledged. The errors are our own. Financial support was provided to T.K. by a grant from the Danish Natural Science Research Council (no. 11-0420-1), and to E.S. by grants CYCIT MAR91-0359 and by travel funds CIRIT EE9342 and CIRIT BE94-529

\section{LITERATURE CITED}

Alcaraz M, Estrada M, Marrasé C (1989) Interaction between turbulence and zooplankton in laboratory microcosms. In: Klekowski RZ, Styczynska-Jurewicz E, Falkowski L (eds) Proc 21st Eur Mar Biol Symp, Institute of Oceanology, Polish Academy of Sciences. Ossolineum, Gdansk, p 191-204

Fenchel T, Jonsson R (1988) The functional biology of Strombidium sulcatum, a marine oligotrich ciliate (Ciliophora, Oligotrichina). Mar Ecol Prog Ser 48:1-15

Frost BW (1972) Effects of size and concentration of food particles on the feeding behavior of the marine planktonic copepod Calanus pacificus. Limnol Oceanogr 17:805-815

Gifford DJ (1993) Protozoa in the diets of Neocalanus spp. in the oceanic subarctic Pacific Ocean. Prog Oceanogr 32: $223-237$

Granata TC, Dickey TD (1991) The fluids mechanics of copepod feeding in a turbulent flow: a theoretical approach. Prog Oceanogr 26:243-261

Holling CS (1959) Some characteristics of simple types of predation and parasitism. Can Entomol 91:385-398

Jackson GA (1994) Particle trajectories in a rotating cylinder: implications for aggregation incubations. Deep Sea Res I 43:429-437

Jonsson PR, Tiselius P (1990) Feeding behaviour, prey detection and capture efficiency of the copepod Acartia tonsa feeding on planktonic ciliates. Mar Ecol Prog Ser 60:35-44

Kiørboe T, Andersen KP, Dam H (1990) Coagulation efficiency and aggregate formation in marine phytoplankton. Mar Biol 107:235-245

Kiørboe T, Nielsen TG (1994) Regulation of zooplankton biomass and production in a temperate, coastal ecosystem. 1.

This article was submitted to the editor
Copepods. Limnol Oceanogr 39:493-507

Kiørboe T, Saiz E (1995) Planktivorous feeding in calm and turbulent environments, with emphasis on copepods. Mar Ecol Prog Ser 122:135-145

Kleppel GS (1993) On the diets of calanoid copepods. Mar Ecol Prog Ser 99:183-195

MacKenzie $\mathrm{BR}_{1}$ Kiørboe $\mathrm{T}$ (in press) Encounter rates and swimming behaviour of pause-travel and cruise larval fish predators in calm and turbulent laboratory environments. Limnol Oceanogr

MacKenzie BR, Leggett WC (1991) Quantifying the contribution of small-scale turbulence to the encounter rates between larval fish and their zooplankton prey: effects of wind and tide. Mar Ecol Prog Ser 73:149-160

MacKenzie BR, Miller TJ, Cyr S, Leggett WC (1994) Evidence for a dome-shaped relationship between turbulence and larval fish ingestion rates. Limnol Oceanogr 39: $1790-1799$

Nielsen TG, Kiørboe T (1994) Regulation of zooplankton biomass and production in a temperate, coastal ecosystem. 2 Ciliates. Limnol Oceanogr 39:508-519

Paffenhöfer GA, Stearns DE (1988) Why is Acartia tonsa (Copepoda: Calanoida) restricted to nearshore environments? Mar Ecol Prog Ser 42:33-38

Price HJ (1988) Feeding mechanisms in marine and freshwater zooplankton. Bull mar Sci 43:327-343

Rothschild BJ, Osborn TR (1988) Small-scale turbulence and piankton contact rates. J Plankton Res 10:465-474

Saiz E (1994) Observations on the free-swimming behavior of the copepod Acartia tonsa: effects of food concentration and turbulent water. Limnol Oceanogr 39:1566-1578

Saiz E, Alcaraz M (1992) Free-swimming behavior of Acartia clausi (Copepoda: Calanoida) under turbulent water movement. Mar Ecol Prog Ser 80:229-236

Saiz E, Alcaraz M, Paffenhöfer GA (1992) Effects of smallscale turbulence on feeding rate and gross-growth efficiency of three Acartia species (Copepoda: Calanoida) J Plankton Res 14:1085-1097

Saiz E, Tiselius P, Jonsson PR, Verity P, Paffenhöfer GA (1993) Experimental records of the effects of food patchiness and predation on egg production of Acartia tonsa. Limnol Oceanogr 38:280-289

Stoecker DK, Capuzzo JM (1990) Predation on Protozoa: its importance to zooplankton. J Plankton Res 12:891-908

Strickler JR (1985) Feeding currents in calanoid copepods: two new hypotheses. In: Laverack MS (ed) Physiological adaptations of marine animals. Symp Soc exp Biol 89 $459-485$

Sundby S, Fossum P (1990) Feeding conditions of Arcto-Norwegian cod larvae compared with the Rothschild-Osborn theory on small-scale turbulence and plankton contact rates. J Plankton Res 12:1153-1162

Tiselius P, Jonsson PR (1990) Foraging behaviour of six calanoid copepods: observations and hydrodynamic analysis. Mar Ecol Prog Ser 66:23-33

Yamazaki H, Osborn TR, Squires KD (1991) Direct numerical simulation of planktonic contact in turbulent flow. J Plankton Res 13:629-643

Manuscript first received: September 5, 1994

Revised version accepted: February 1, 1995 